\title{
URBAN PRIMACY IN URBAN SYSTEM OF DEVELOPING COUNTRIES; ITS CAUSES AND CONSEQUENCES
}

\author{
Seyed J. Faraji ${ }^{1, a}$ \\ Zhang Qingping ${ }^{\mathrm{a}}$ \\ Saman Valinoori ${ }^{\mathrm{b}}$ \\ Mohamad Komijani ${ }^{b}$
}

\author{
Original scientific paper
}

Faculty of Landscape Architecture, Nanjing Forestry University, Nanjing, China ${ }^{a}$

Faculty of Geography and urban planning, Kharazmi University, Tehran, Iran ${ }^{b}$

Received: 16.01 .2016

Accepted: 21.02.2016
UDC:711.4:911.375.1

$316.334 .56(1-773)$

364.652.4:911.375.1

\begin{abstract}
In the current world, cities have become the main arms of the actuator in the movement of social system of human communities. Nevertheless, urban systems in developing countries, despite the vast potentials, are faced with serious problems such as rapid urbanization, constant migration of rural people to cities, and concentration of population and activities in one or two cities, or, in other words, urban macrocephaly. Despite the primacy or dominance of one city in some developed countries, we do not observe clear negative features of urban primacy; on the other hand, although it is not evident in all countries of the developing world, there are evident features of urban systems in most of these countries. This paper aims to identify and understand the formation of the phenomenon of urban primacy in developing countries. The method of this study is descriptive-analytical and is based on document studies and the results of different urban projects in different area of the developing world and it is responding to these questions about the background and causes of the formation of urban primacy in these countries and its consequences of this phenomenon which led this conclusion that this phenomenon should be analyzed from different dimensions of economic, social, cultural, historical, and political and lastly its causes and consequences should be observed with regard to these dimensions.
\end{abstract}

Keywords: Urban Primacy; Developing Countries; Causes and Consequences of Urban Primacy

\section{INTRODUCTION}

Today, the urban population growth in the less developed countries of Asia, Africa and Latin America is happening as an explosion. Currently, most population congestion or gatherings in cities no longer occur in the developed world but in the developing world. According to the estimates, the world urban population will pass the border of 5 billion by 2025 of which over $\% 90$ will be in developing countries
(Ahmadi et al., 2013). At the threshold of the new century, there are seven cases of then large cities in less developed countries of which Mexico City, Sao Paulo, Mumbai, Lagos, and Jakarta can be referred (Kim le, 2002: 3). According to a UN forecast, of 27 metropolitan cities with a population of over 10 million people by 2015, 18 will be in Asia (Hall \& Faifer, 2009: 13).

\section{${ }^{1}$ Correspodence to:}

Faculty of Landscape Architecture, Nanjing Forestry University, Nanjing, China

E-mail: f.jalalfaraji@yahoo.com 
Table 1 Regional Distribution of Hundreds of Major Cities around the World

\begin{tabular}{ccccc}
\hline Africa & 1800 & 1900 & 1950 & 2000 \\
\hline Asia & 4 & 2 & 3 & 8 \\
Europe & 65 & 22 & 36 & 45 \\
Latin America & 28 & 53 & 35 & 15 \\
North America & 3 & 5 & 8 & 17 \\
Oceania & 0 & 16 & 16 & 13 \\
\hline
\end{tabular}

Surce: McGranahan (2002)

Increasing growth and trend toward high urban concentration and consequently urban primacy are of characteristics of urbanization in developing countries. Totally, the urban primacy law is applied when the biggest city hosts lots of national population. Urban primacy is said to a city which has accommodated a population more than twice as much as that of the second largest city of country. Index of urban primacy is calculated by the division of the population of the largest national city to that of the second largest city (Short \& Kim, 2010: 217).

Meanwhile, the phenomenon of urban primacy is not limited to the developing countries but it is also experienced by 19th century European countries when they had just begun urbanization and industrialization. The population of London had been $\% 62$ of population of Britain in 1800 and \%54 in 1900. Despite the increase of industrial cities in northern France, Paris had \%64 of urban population of France in 1900. London and Paris have kept their dominance from the beginning (Roberts, 2003: 9). Still, simultaneous with this phenomenon, we do not observe negative features of the urban primacy in these countries which is present in developing countries. Moreover, some of developing countries do not show urban primacy; for example, China and India are big countries with large cities but they do not have a real dominant city. Still it can be said that urban macrocephaly and its characteristics are considered as undeniable and evident aspects of urban systems of these countries.

In this regard, the index of urban primacy in Mexico City is $5 / 3$ in proportion to Guadalajara, the second largest city of Mexico. Almost one out of 5 Mexican people live in metropolitan area of Mexico City. Likewise, index of urban primacy is 10/5 in Lima, capital city of Peru. This means that $6 / 5$ million people of 25 million population of this country live in metropoli- tan city of Lima. In Uruguay, one of every two people lives in urban primacy of Montevideo. Bangkok in Thailand, perhaps more than any other metropolitan area in the world, displays primacy and dominance (Fr Gerald, 1980: 14) and with7/5 million people is 18 times more populated than the country's second largest city Nonthaburi (Short \& Kim, 2010: 218). Cairo, the largest urban area in Egypt, Africa, the Middle East and one of the most populous metropolitans of the world has more than \%15 of total Egyptian population while Alexandria, the second metropolitan city of Egypt, only has $\% 5 / 4$ of the whole population (Huzayyin et al. :2009). Greater Tehran includes more than \%11 of Iran's population. While the religious metropolitan city of Mashhad, as the second most populated city of country, only does include $\% 4$ of the whole population (Statistical Center of Iran, 2011).

This macrocephaly is not solely limited to population dimension and it is completely evident in economic dimension in a way than among 75 countries which have had a per capita income of less than 1500 US dollars, 55 countries have had serious urban primacy and dominance (Piran 1989: 48). Lima holds more than $\% 43$ of gross domestic product (GDP) of Peru. Manila has taken over $\% 13$ of population and $\% 33$ of Philippines' GDP and Sao Paulo has likewise taken over more than \%40 Total Value Added of Brazil. In many other cases the situation is similar. Therefore, using descriptive-analytical method and relying on document and library studies and while reviewing characteristics and dimensions of urban primacy phenomenon in some developing countries, explanation of its background and causes of formation and also investigation of the effects and consequences of this phenomenon in urban systems of developing countries are dealt to. 


\section{REVIEW OF LITERATURE}

Discussion about urban systems in developing countries, mainly in the form of literature has been developed. In other words the development schools, including school of modernization, dependency theory and global system theory each has in a way dealt with the discussion of urban system in less developed countries. Modernization school not only do not consider imbalance in urban systems in developing countries as undesirable but also knows it to be inevitable because based on the doctrine of modernization, least developed countries are forced to travel the same path, in all fields including urbanization, that the developed countries have traveled. This school, a fan of uneven development, later on paved the way, in form of some theories like growth pole, for urban macrocephaly in most of developing countries. But the approach is different and opposing the modernization school of the dependency approach based on the work of Andre
Gunder Frank, a Chicago School economist. Frank said that development and underdevelopment are two sides of the same coin, and both a consequence and a manifestation of the contradictions of capitalist development are required, based on his reasoning, inertia consequence conditions in developing countries, wretched, luck, and fortune, climate, or anything else but due to the country's accession process to the global capitalist system (Potter and Evens, 2005: 77). Frank argues about the situation in Latin America which is in a way the source of dependency theory that Iberian conquests in America before Columbus absorbed into the capitalist world economy as a result of the merger surplus Spain (in the form of silver) and Portugal (as cotton, sugar and gold) were to be economically Later, when Spain and Portugal, were related to industrial Britain, Great Britain took it over the head. Thus the excess wiring was connected to the chain growth in Latin America, Great Britain, and had kept the growth (Gilbert et al. 1996: 37).

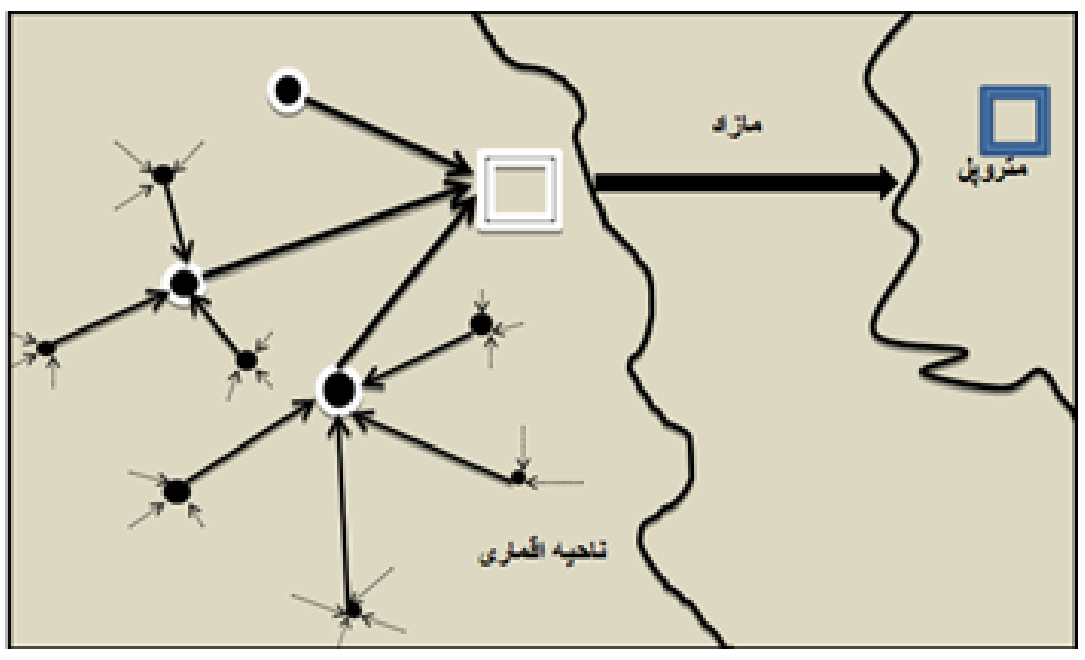

(Adapted from Potter and Evens, 1998)

Figure 1 Geographical Representation of Dependency Theory

As it is displayed in above figure, the main and important point in Frank's dependency theory is metropolitan-satellite pattern in which global urban system starts from the main metropolitan city and ends in rural and urban points around it. Frank imagines global capitalist system as a hierarchical or pyramid structure of which base is located in rural surroundings. Based on World System Theory of Immanuel Wallerstein, global city is a hierarchical system that includes four international cities or Mother global centers that are the National Metropolis Third World, Third World regional centers and rural areas and small towns that like dependency theory, this model also transfer the surplus to the world metropolis of regional centers and metropolitan cities to be done nationally (Azimi, 2002: 115).

In addition to the development of ideas, discussion about urban hierarchy had been raised by people like Cristaller and Lush but conceptual project called urban primacy and investigation and measuring it was explicitly done for the first time by Mark Jefferson 1939 in a paper titled "The Law of Urban Primacy." 
For explaining the phenomenon of large cities in which a great part of the population and economic activities of the country is concentrated and mostly are the capital cities, he used the title primacy. In his opinion, primacy, in the urban system of developing countries in proportion to those of developed countries, is proportionally larger than the second and third cities of these countries (Jefferson, 1939. 226-232). Assessing urban primacy and providing indexes for it was continued after the pioneering work of Jefferson by others such as Zeepov, Williamson, and Henderson. Zeepov (1941) attracted attentions to the entire urban system by providing the law of rank-size. He claimed that in a homogeneous system of social - economic rule out that - as is true and this is when a country's urban system has reached an equilibrium state (Zebardast, 2007: 31). Further studies to assess the primacy's urban systems in different countries have a number of researchers who have examined the causes of it. Brian Barry in 1961, does not fond a significant relationship between the size distribution of a country and its level of urbanization and the distribution of city size and level of economic development. So he sees a set of variables involved in the creation of the urban primacy. According to Arnoldovslky (1965) urban primacy definitely depends on the country's export orientation, population, labor force employed in the agricultural sector and the overall rate of population growth of a country. According to Linsky, urban primacy is of specific characteristics of small countries with low per capita income, their high dependence on exports, the history of colonial agricultural economy, high growth rate of agriculture. Vapnarsky (1969) has seen urban primacy as a relationship with a certain degree of economic blockage that its dependence on foreign trade is considered (Potter \& Evens, 2005: 100). Urban primacy has been followed in the past decades by people like John Fridman and ...but these researches have been after development and investigation of the causes and consequences of this phenomenon of which case this study exists while knowing the defects that exists in general generalization; it considers the developing world as a unit and tries to provide a comprehensive analysis of the condition of primacy in these countries and explains its causes and consequences on urban systems of the mentioned countries.

\section{URBAN PRIMACY IN THE DEVELOPING WORLD}

\section{A_Urban Macrocephaly in Asia}

The developing world is developing in a way that attempts to generalize its related conditions are very complicated in the best condition. Regional analytical method undoubtedly has many defects because there is no psychological quality in certain geographical proximity which makes the neighboring nations literally a unit whether cultural, political, or economical (Mirdal, 1987: 23).

Asia is a disparate and heterogeneous geographical unit which discussing it as a whole must be thoughtful and cautious. Regarding urbanization of this continent it can be said that it has much different quality and quantity which oscillate from regions with \%100 urbanization like Hong Kung and Macao and the North Korea in Eastern Asia to less urbanized countries of the middle and southern Asia. This heterogeneity is evident within regions, for example in South Asia, the percentage of urbanization of Iran is $\% 69 / 1$ and in Sri Lanka is only \%15/1 (United Nations 2011: 122). Most urban population growth in Asia in recent years has been in Bangladesh, China, India, Indonesia, Pakistan and the Philippines. In 2008, of the world's 17 megacities, 12 had been in Asia, and in 2015, 18 out of 27 of the world's megacities will be in Asia five of which are Mumbai, Delhi, Calcutta, Dhaka and Karachi. Now also in Pakistan and Bangladesh excessive growth of Karachi and Dhaka cities has caused them to be dominated on economic of their countries. For example, not only Karachi has \%12 of Pakistan's 160 million population, but also it has between 60 to 70 percent of national income and more than $\% 40$ of value added in manufacturing (Gupta \& Rayadurgam, 2008:2). Population of over 12 million people in the major cities and nearly 17 million in the metropolitan area has made Dhaka to become one of the world's greatest metropolitans in 2003, ranking eleventh largest cities in the world (Kabir \& Parolin, 2007: 2) and has been in the seventh rank with a population near 16 million (United Nations, 2011: 26). Dhaka has also the highest growth rate $(2 / 3)$ in the metropolises of the world and each year hosts around 300 to 400 thousand people, mostly poor immigrants (Kabir \& Parolin 2007: 2). 
Table 2 Urban Primacy in South Asia

\begin{tabular}{ccc}
\hline & urban two index & urban four index \\
\hline Bangladesh & 3 & 1.9 \\
Pakistan & 1.85 & 1.2 \\
India & 1.2 & 0.5 \\
China & 1.4 & 0.5 \\
\hline
\end{tabular}

Source: Shreektan Gupta (2007)

Metro Manila, the Philippine capital and dominant city in East Asia with an area of just 636 square kilometers, a population of nearly 12 million in 2007 and a high density of 18,650 persons per square kilometer has allocated $13 \%$ of the population of the Philippines to itself. Metro Manila, both domestically and internationally, is synonymous with the Philippines and the Filipino community. $78 \%$ of the metropolis, financial services, $53 \%$ of transportation and communication, and $38 \%$ of the industrial sector in the Philippines is in possession of Metro Manila (Pario, 2009: 24).

Bangkok, known as the Venice of the East (Fry 1980) is a prime example of a perfect city. In 2010 more than 8 million people live in this city, near to the $\% 12 / 5$ of the total population of empire in Thailand, while Thailand's second city only has a population 166 thousand people. High density of 5258 persons per square kilometer in the density of 127 persons per square kilometer in Bangkok, Thailand, is also indicative of this macrocephaly (NSO ${ }^{2} 2010$ ).

Middle East and Persian Gulf countries also display pattern of urban concentration in a somehow similar form. Turkey and Jordan are the only Middle Eastern countries that size distribution and hierarchy of cities and their ranks do follow Zeepov's law. Iran, Iraq, and Kuwait have one completely dominant city on countries' urban network (Costello, 2004: 82). Tehran's demographic changes and it extremely well development indicates that it complies with the law of primacy and single-city dominance in Iran's urban system (Piran, 1989: 45). Tehran had allocated to itself in $2004 \% 26 / 9$ of GDP, \%17 of value added in mining and technology, $\% 73 / 5$ of value added in the service sector, $\% 32$ of the country's faculty members, and \%20 of state-run Iranian students (Rezaei \& Pour Ahmad 2009: 64). In many other Asian countries the conditions is similar with a slightly different situation.

\section{B_Urban Macrocephaly In Latin America}

Wave of urbanization has been running in the developing world in the past half century, but in no region is crisscrossed like Latin America's urbanization has been mightily. Latin American urban population has reached from $40 \%$ in 1950 to over $65 \%$ in 1980 which this percent has not been far from that of North America (\%73/9) and Europe (\%70) but is much higher than that of Asia (\%26) and Africa (\%27). According to a 2007 UN Habitat Latin America has the highest urbanization rates in the world. In the twenty-first century, more than three quarters of the population in Latin America are urban which this figure will increase to over $\% 85$ by 2030 (Rodgers et al. 2010: 2 ). Nearly $80 \%$ of the population of Argentina, Brazil, Chile, Cuba, Uruguay, and Venezuela has been living in cities in 2000. On the other side vector, Guatemala, Haiti and Honduras have less than 50\% Urban (Bera, 2003: 13).

Table 3 Primacy Gatherings of a Population of More than 5 million in Latin America Between 1950 to 2015

\begin{tabular}{cccc}
\hline 2015 & 2000 & 1975 & 1950 \\
\hline Sao Paulo & Mexico City & Mexico City & Sao Paulo \\
Mexico City & Sao Paulo & Buenos Aires \\
Buenos Aires & Buenos Aires & Rio \\
Rio & Rio & \\
Lima & Lima & \\
Bogota & Bogota & \\
Santiago & Santiago & \\
Bielefeld Hvryznth & & \\
Guatemala City & & \\
\hline
\end{tabular}

${ }^{2}$ Source: Brea (2003: 26) 
Although urban dominance is a common phenomenon in the most third-world countries, Latin America, in proportion to that of other parts of the world, has a different and out-of-the-norm situation and some of Latin America's countries show the highest indexes of primacy and urban dominance. There are clear examples of the first city of Santiago and Lima. Santiago in 1875, had a population of only $1 / 3$ against Chile's second city of Chile, Valparaiso, while in 1970 was 7 times and in $20007 / 5$ times greater. Lima in 1940 was 8 times, and in 200010 times larger than the second largest city in Peru's Arkupya. Lima in 2012, with 6/7 million inhabitants, had allocated to itself more than $25 \%$ of Peru's population of 30 million. The capital of Costa Rica, Panama, Guatemala and the Dominican Republic are much larger than the other cities of this country. In Brazil and Colombia, urban primacy is so high because investment in secondary cities like Sao Paulo and Medellin has caused more growth than that in the cities of Rio de Janeiro and Bogota (Bera, 2003: 30).

Table 4 Index of Primacy in Latin America Countries and Caribbean Sea region (1995)

\begin{tabular}{ccc}
\hline Country & Urban dominance index \\
\hline Argentina & 3.5 \\
Bolivia & Brazil & 0.9 \\
Columbia & 0.9 & 1 \\
Chile & 3 & 1.1 \\
Ecuador & 6.9 \\
Guatemala & 6.1 \\
Honduras & 2 \\
Mexico & 2.8 \\
Nicaragua & 3.9 \\
Panama & 5 \\
Paraguay & 4.1 \\
\end{tabular}

Source: Rodgers et al. (2008)

While opinions vary, many believe that urban macrocephaly history in Latin America goes back to the early nineteenth century and even before. Morse, using the measure the proportion of the population of the largest city as a means to measure urban primacy, concludes that urban macrocephaly started in Argentina and Cuba in 1800, in Colombia, Mexico and Peru in 1850, and in Brazil and Venezuela in 1900 that in all these cases the dominant city had been the capital of the country. McGregor, also using measured the Pareto distribution index, shows that the beginning of primacy had been in early 1750 in Cuba, 1825 in Mexico, 1830 in Chile, 1850 in Argentina, 1925 in Peru, and 1950 in Venezuela and Colombia and points out that today all Latin America countries maybe other than Brazil and Colombia significantly display characteristics of urban primacy (Galiani et al. 2008).

\section{C_ Urban Macrocephaly In Africa}

Africa has had the fastest growth rate of urbanization but it is still less urbanized compared to other areas. In 2009 , almost $\% 40$ of the population of Africa has been living in urban areas (Nwanna: 2012: 3). In 2010, Africa had 47 cities with population of more than a million that Cairo, with more than 11 million people population had been at the top of urban hierarchy of Africa. Lagos, with 10/5 million people, Kinshasa with 8/7 million, and Luanda with 4/7 million population are after Cairo. Alexandria and Abidjan are other big cities of this continent (UN Habitat: 2010).

Urban primacy rates or the proportion of the population than the largest city in Africa and the Middle East, Latin America and the Caribbean is low and the urban landscape of the continent is dominated by large cities. Only $12 \%$ of the urban population in Africa lives in urban settlements with populations between one and five million people. In recent decades in which the public's attention has been focused on the growing metropolises of over 10 million people, or large cities with a population of 5 million, in Africa, in 1970, no cities with the above characteristics has been found and in 2000, just three cities of Cairo, Kinshasa and Lagos are among the latter. 
Greater Cairo, the largest metropolitan area in Egypt, Africa, the Middle East and one of the world's most populous Metropolitan, has more than $15 \%$ of the total population of Egypt while the city of Alexandria, Egypt's second largest concentration constitutes only $\% 5 / 4$ of the total population of the country (Huzayyni, 2009). Lagos, as an urban primacy, has grown faster than any other cities in the African desert fringe. While the city is one of the smallest states in Nigeria but with a population of nearly 15 million people, is the largest city of Nigeria and the second largest city in Africa and the sixth largest city in the world (African Research Review 2010: 2). Although urban macrocephaly in Africa continent is less than that of the other parts of the world, the largest city in every country is accounted for a disproportionate share of the national economy. For example, in Addis Ababa, with 2/6 million people, includes only $4 \%$ of the total population of Ethiopia but it has allocated to itself more than one-fifth of the country's GDP (World Bank, 2003).

Sub-Saharan African countries have shown unprecedented urban growth. Urban population growth in the area with over 5\% a year over has doubled 15 years. Import substitution policy which was followed after political independence by many African countries has been associated with urban flavor. The focus of these countries on industrialization, complicated technologies, modern education and training, and the growth of metropolitan cities led to a lack of equilibrium in economic and non-economic opportunities among rural and urban areas of which consequences was extensive immigration of rural areas to cities. Although industrialization strategy failed in sub-Saharan Africa, but Africa's urban growth area continued.

From 1900 when part of the continent of Africa was obtained, 25 of the 35 capitals of countries that had access to the sea coast were located in coasts. These cities developed as centers of economic activity and extended their domination. 15 of the 25 coastal colonial capitals in 1900, in 1991, still retained its position as the premier city (Pholo Bala, 2009: 3).

\section{THE REASONS AND FACTORS CAUSING UR- BAN PRIMACY}

In explaining the reasons causing urban primacy it certainly cannot be taken a one-sided and limited look at it. Thus, it is attempted in this study to, with a more comprehensive look, analyze and investigate the context, social, economic, and political causes and factors, which are somewhat common in most of developing countries, which has been a bed for the existence of urban primacy. Therefore, a set of internal and external factors that are involved in creating the phenomenon of urban primacy can be outlined as follows:

\section{Economic Dimension:}

Economics is one of the most influential factors in the formation of urban primacy phenomenon. Today, economic principles define themselves in terms of production, distribution, import and export. Thus, those countries which have these four dimensions of capability are faced to a remarkable unity and system, but those countries which lack and have defects in this aspect face with serious problems. With a look at the phenomenon of urban primacy and with regard to the economic dimensions dominant on the total atmosphere of that country, one can understand the economic defect of that country. Looking at the economic structure of many countries which are faced with the problem of primacy, we understand the connection between these two issues. Although concentrated economic structure can be both cause and effect of primacy, what is evident is that in most of the countries which have been previously referred to, we observe defects in economic structures and mechanisms and manufacturing, distribution, and consummation systems. One of almost common characteristics of these countries is the single-product economy and high dependence of these countries on this kind of economy. In fact, having traditional economics dependent on one or two products and the dual nature of economic activities in this kind of countries can be considered as one of the causes of the emergence and persistence of urban primacy. Growth of large cities in third world countries has been associated to increase in production for export and international trade. The causes of growth of Sao Paulo city has been production and export of coffee; Accra, production and export of cocoa; Kolkata, manufacturing and exporting jute and textile; and Buenos Aires, production and export of sheep meat, wool and grain. (Gilbert \& Kaglr 1996: 78). Moreover, while in developing countries the production mix of agriculture change from rural economy towards manufacturing and services, technological and using technology (capital), labor from the agricultural sector becomes free and migrates to the cities. 
This change of composition of production causes urban development because firms and individuals in cities are assembled in order to be able to benefit from the local and town saves caused bf scale in manufacturing and services (Henderson, 1974; Fujita \& Ogawa, 1982; Helsley \& Strange, 1990; Doranton \& Puga, 2001). Due to the local economy of scale, the manufacturing and services in the areas of business - the industry is concentrated in urban area and it is very efficient. Spatial proximity or high concentration of activities in a place increase the overflow of information among producers and make more efficient the performance of the labor market. From the other side the costs of transportation and exchange of products among producers and also costs of transport for citizens decrease and create external positive and remarkable consequences (Henderson, 2000) and thus further considerations of city and urban system happens.

\section{Social Dimension:}

Urban primacy foremost is a social and population issue, and the definitions of primacy have essentially had population look. Thus, the increasing rate of population growth and urbanization that followed a different path has come from developing countries; urban areas have been the first formation mechanism. In developing countries population explosion in those areas can be known to be caused by population growth and high rate of migration from rural areas into cities (Fokohi, 2006: 106). The phenomenon of rapid urbanization in these countries in particular, highlights after 1950s because the majority of the population lived in rural areas of Third World countries. Less than one out of every six people lived in cities and towns in China, Southeast Asia and most of sub-Saharan Africa. Indeed, throughout Africa, Asia and Latin America Latin America, the only region of the temperate zone of Japan and the majority lived in urban areas. Since 1950 urbanization became a worldwide phenomenon. Rate of change varies between countries and regions but almost all Third World countries became urban fast (Gilbert \& Gagler, 1996: 24). Along the 20th century, Latin America changed from a big rural community into one of the most urbanized areas of the world. In fact, in the early twentieth century, nearly $90 \%$ of the population lived in rural areas, but in Latin America between 1950 and 2000, urbanization in Latin America increased with a growth rate of $\% 3 / 5$ and the urban population rose from 65 million in 1950 to reach 380 million in 2000 (Brea, 2003). In early 2oth century, African Desert fringe was almost with no city which its urbanization growth has been $0 / 5$. (Jedwab, 2011: 2). But this process is changing now. It is a fact that the main reason of this growth of urbanization is not the natural growth of urban population but it is the migration from rural areas and towns into metropolitan cities and this migrations, which are mostly economicbased and have been done caused by an economic priority, are themselves caused by weakness of economic structure and programming system; thus, it seems that in the investigation of the causes of urban primacy, we face a causal chain that act as intertwined. For example, studies in Mali, Nigeria, show that in $\% 50$ of rural families in ordinary areas and in $\% 80$ of families in dry-prone areas have a emigrated member (UN, 2008) and this is in a way that the high rate of poverty in laborers in subSaharan Africa is in a way that more than $\% 64$ of these people have an income of less than 2 dollars per day and unemployment rate among the young is \%24 (Kabiru, 2013) and totally about $\% 88$ of people are jobless or have a miserly income. In Latin America countries, unemployment rate is also increasing in a way that between 2008 and 2009 more than 2.5 million people is added to 18.2-million population of this country (UN) and this jobless population has gone to metropolitan centers with better labor market.

\section{3_Political Dimension:}

Centralized political systems that their approach of planning and development are authoritarian and top-down model are the urban primacy incentives because urban primacy are mainly capital cities and are headquarters and a symbol of the political life of the countries. In developing countries, supportive policies of governments from one or more large political cities and usually the capital cause much focus and with the development of infrastructural investments in these cities, the attraction of residence in them also increases and causes the attraction of agencies and many people to them. In urban literature, this issue with the title of making exception by the national government in dealing with the capital city and political cities will be examined. The more the independence of local governments, the lesser the increasing concentration on one or more large cities due to specific discrimination policies of the central government (Henderson, 2000). For example, different evidences show that urban macrocephaly in Latin America is related to the concentration of the central government in the capital which Mexico City is a good example for this issue. Since the time of Aztecs to the time of Spanish colonial period, Mexico City, as a political center, acted military, had constantly dominated on the adjacent regions and their boundaries. 
Urban dominance in most cases is together with high level of political instability and political systems and because of this dominant cities in instable dictatorships are $50 \%$ more stable than stable democracies. Political center of the city is undoubtedly an essential role in establishing dominance. Henderson has shown that the dominant political capital cities are $25 \%$ higher than the first cities that do not have the political center of the country (Overman, 2005: 24) in this regard it can be referred to the capital of the Philippines, Manila, the capital of Lima Peruvian, capital city of Iran, Tehran, Egypt's capital Cairo, Baghdad, capital of Iraq and ... and should be noted that they have reached primacy by political dominance.

\section{Historical Background:}

Of other factors that are mentioned as the causes of the formation of colonial cities in these countries is the colonial background. Colonialism of Iberian in Latin America which lasted for more than 300 years caused the creation of a big network of cities that had the power in their control both symbolically and materialistically. In 1900, most Latin Americans lived in the countryside and only three cities had over half a million inhabitants. Industrialization and capitalistic product together with the entrance of the logic-centered reason in early 1930 s accelerated urbanization and has continued during the past 70 years in a way that now more than 40 cities exist in this area with populations of more than one million (Rodgers et al. 2010, 2). The role and presence of the colonialists in creation and emergence of this phenomenon in addition to Latin America is well evident in African countries because in that time sea port had a crucial role for export and import of raw material of colonies and importing factory goods from colonizer countries. As time passed, these ports became bigger both geographically and with regard to its population and changed into dominant positions and entered into the urban systems of these countries with no reasons in a way that despite the formation of political independence in these countries, still remarkable changes are not visible in spatial distribution of economic factors in these urban systems and even in cases that the capital is moved from a border city to a inner position, the border city still kept its dominance. This is visible in Ivory Coast, Nigeria, Cameron, and Tanzania in which places the capital is moved from Abidjan to Yamoussoukro, from Lagos to Abuja, from Duala to Yaoundé, and from Dar Al-salaam to Dodoma (Pholo Bala, 2009: 3). In Asia as well, such ports in the estuaries of rivers, navigable waters and areas where production and internal communication lines are connected to each other, have been constructed, for example, Colombo was able to cover the flow fields of all over the Philippines Manila's Jakarta all Indonesia where production on a commercial scale in Java and Sumatra is concentrated along the eastern coast (Gilbert \& Gaglr 1996: 79).

\section{CONSEQUENCES OF URBAN PRIMACY AND DOMINANCE}

Urban primacy, as a present fact in urban network of developing countries which shows the lack of equilibrium and abnormality of urban system of these countries, undoubtedly has effects and consequences that can be investigated in economic, social-political, and management dimensions.

\section{Economic Consequences:}

There are two conflicting views on the economic implications of the phenomenon of urban primacy. Some consider urban primacies as country's economic growth engine and deem they as indicators of economic centers and social power and they both benefit from their own economic groups and comprehensive public services and the powerful social network which provide for the poor. Some others consider urban primacies as a blockage of economic growth and they believe that the excessive concentration of population lead to increasing rise of negative effects such as congestion, inefficient use of national space and proper use of urban areas (Short \& Kim 2010: 221). In this regard, Henderson believes that the degree of urban concentration is effective on growth and efficiency of the national economy but unfortunately this growth is not linear, this means that with the increase of concentration, first economic growth rises and reaches the highest point and then, with more increase of urban concentration, economic growth gets a reverse decline and decreases (Farahmand et al. 2009: 4). He believes that (2003) urban primacy outside of the norm has a significant negative impact on economic growth. In fact, the relationship between primacy and economic growth is an inverted ' $u$ '; in other words, the more primacy be bigger than its optimal size, the more its negative impacts of economic growth. (Overman and Venables: 2005: 24). It appears that the latter may be more accurate view of the first cities in the developing world because the parasitic prime city center properties has led to a growing economy. Looking at the economic development of these countries shows that cities are the economic engine of the prime cities has failed, but they have put in isolation and economic dilemma. 
For example, Metro Manila in the Philippines has allocated to itself the highest volume of international trade of Philippines, $\% 78$ of financial services sector, $\% 53$ of transport and communication sections, $45 \%$ of services, and $38 \%$ of the industrial sector. (Porio, 2009: 20). Lima, capital city of Peru, has allocated to itself about half of the country's economic activity (61\% of GDP of factories and industries sectors, $\% 56$ of the construction sector, $52 \%$ of services, and $9 \%$ of GDP of the agricultural sector) (Weeda, 2012: 11). $\% 29$ of GDP in Colombia is in Bogotá and per capita income in it is \%50 more than the whole country. But evidences and economic indicators show that this increasing economic concentration is not in line with the development of the mentioned countries.

\section{2_Social Consequences:}

One of the consequences of urban primacy, which reinforce both in forms of problems and also as social problems, is urbanization of poverty. Concentration and accumulation of vast areas of poverty and inequality in cities has led to many problems. The concentration of poverty is the result of accumulation of mass migrants which have taken refuge in the city, but the city has been absorbed into the economic system. One of the manifestations of poverty is marginalization. In this regard, we can say that today almost all of the urban primacy in the developing world is grappling with the problem of marginalization. For example, from 1990 to 1991 it was estimated that $47 / 9$ million, or $60 \%$ of the population in Mexico City live in self-help housing; in the same year, $61 \%$ of residents living in Caracas, \%60 in Bogotá, $70 \%$ on the shelter subsisting Casablanca (Potter \& Evens, 2005: 213). In 2006, $65 \%$ of residents of Cairo have been living in informal settlements. $\% 28$ of the built residential units from 2003 to 2008 in this city have been in informal areas and 3 cases of 30 slum areas of the world exist in greater Cairo with a population of about 8 million people (Habitat, 2011: 18). Primacy of Bangladesh, capital Dhaka, has the fastest growing rate in the world in a way that between 300 to 400 thousand immigrants migrates, mostly rural, to this city each year. The rate of growth in Dhaka has been constantly above $\% 7$ in recent three decades and much slum areas have grown around it. Between 1996 and 2005, the population of slum dwellers has doubled and has reached from 1.5 million to 3.4 million people. Dhaka has more than $\% 34$ of the whole population of Bangladesh and slums around it, though only occupied $\% 5$ of the city, it has kept more than $\% 34$ of the population of city with a density of 891 people per acre and $\% 85$ of them live below the poverty line (Abdul Mohit, 2012: 612). In other urban primacy of the developing world, the conditions are similar. Moreover, the age structure of cities of the developing countries which are young due to the emigration from one side, anonymity and being hidden in metropolitan life from the other side also cause dissemination of social problems in these cities in a way that crimes and delinquencies are increasingly rising every day. In this regard, it can be referred to high violent crimes in Colombia and Bogota and this is in a way that the rate of economic growth of Colombia has been constantly more than the average rate in Latin America in recent decade and poverty also has declined from $\% 54$ to $\% 46$ between 2002 and 2012, but according to the World Bank, the Coefficient of Pocket has always been very high in Colombia (/559) and economic gap between the poor and rich is still great that this can be one of the causes of violent crimes in this country (Wessels, Pardo \& Bocarejo, 2012: 9). But, what that draws attentions to primacy and makes its social damages more than ever, is the terrible statistics of crimes in Karachi, Pakistan; Rio de Janeiro in Brazil, and Baghdad in Iraq; these cities are of top ten crime cities of the world (www.mapsofworld.com). Mexico City and some other cities of southern Africa which have high statistics of crimes should be added to the list of these cities.

\section{Cultural Consequences:}

Urban primacy in developing countries are centers of manufacturing facility, distribution and control culture in all its aspects to the cultural cities such as packaged goods, manufactured and supplied by the cultural dominance of political domination, economic, social and even psychological Mother city. In the less developed world, although metropolises are a mixed amalgam of various cultures and traditions, they continued to try to shape the culture of one of the most influential cultures, languages and dialects spoken in the countries. Countries which has urban primacy are rapidly losing their dialects and reaching the first spoken language of the political primacy because extensive influence of wealth and media of these cities have overshadowed other aspects in the city. Linguists estimate that there are currently 6,800 living languages in the world $90 \%$ of which have less than one hundred thousand speakers and this means the extinction and destruction of the development process of languages (Bashir Nejad, 2004). 
The sample of this is the destruction and extinction of various dialects of Persian language in Iran overshadowed by Persian language in Tehran, Chinese is overshadowed by (Mandarin) in Beijing, Thailand overshadowed by newer languages (Thai) in Bangkok, Latin American is overshadowed by Spanish, and the like. It seems that other dimensions of culture like clothes, local customs, etc. are being eroded and extinct under the influence of mental superiority of the culture of primacy.

\section{Political Consequences:}

The political consequence of primacy is mostly mentioned regarding security aspect. As mentioned, most prime cities of developing countries are centers of political and national capital. This intense political activism is known as a security challenge for these countries in a way that has made most of these countries, with different political systems, to think about change of capital city. The passive defense has led the city to look at the vulnerability in case of any incident, whether natural or man focused. In countries that the political and economic concentration is in one city, in case of decline of the primacy caused by natural events like earthquakes or by war or civil upheaval, the government will fall. Iran's Islamic Revolution in 1979 in Tehran by taking control of the revolutionaries, United States of America War of Iraq and overthrow of Saddam Hussein falling in Baghdad in 2003, the recent revolution in Egypt in 2011 and the crash of Gaddafi in Tripoli and control Libya the revolutionaries (although the specific reasons for the conflict was the center of Benghazi) are some examples of these cases.

\section{CONCLUSIONS}

Primacy and dominance of one city in urban system of countries is a phenomenon that is sometimes seen in developed countries; but, due to the different nature of urbanization of these countries, it is not of metropolitan mode in these countries. In other words, it can be said that this phenomenon is a special feature of urbanization system in most developing countries and shows the extrinsic urbanization mechanism and defect in the structure and function of urbanization system of these countries. In fact, it appears that although the history and geography of developing countries is different, the mechanisms and the range of factors that have led to the formation of urban primacy effect in most of these countries have significant similarities. In this study, high population growth, rapid urbanization which is largely a product of migration, focus oriented economic system, less democratic and centralized political government, colonial history or something like that, are identified of formation grounds of urban primacy. On the other hand, in most cases, factors and backgrounds act in intertwined form and have causal and synergy action. In other words, in all urban primacy which has been briefly mentioned, various political, social, economic, and cultural factors, in relation to each other, have been leading to the formation and persistence the urban primacy. Interestingly, primacy, regarding effects and consequences, in most cases has led to a form that has caused abandonment of urban systems, poverty, increasing marginalization, crime and delinquency in these countries; and the whole of political, social, economic and cultural vulnerabilities of developing communities in various aspects of the consequences have been resulting from primacy in these countries. In this regard, a comprehensive understanding of the problems can be a key to solve and remove blocks and problems around developing communities at national and international levels and such studies can well be helpful for national and international institutes.

\section{REFERENCES}

Abdul Mohit, M. (2012). An Assessment of Policy Approaches Adopted to Deal with Bastee Settlements of Dhaka City in Bangladesh, Asian Journal Of Environment-Behaviour Studies, 3(9)

Ahmadi, R., Monfared, S. \& Torabi , Z. (2013). Analysis of formation of urban primacy in Khuzestan province during 1956-2011, Journal of Economic and Social History, Year II, No. I, pp. 19-50.

Azimi, N. (2002). Principles of urban systems and dynamics of urbanization. Mashhad: Nika press

Bashir Nejad H. (2004). Extinction of local languages in Iran, Iranian Culture Magazine, 5.

Bera, J. A. (2003). Population Dynamics in Latin America. A publication of the Population Refeferenc Bureau, 58(1)

Costello, V. F. (2004), Urbanization in the Middle East, translated by Parviz Piran p. and Rezai A., third edition, Tehran: Nai Press

Farahmand Sh. ,Tayebi S. K., \& Akbari N.A. (2009). Effects of urban primacy on economic growth

Fr Gerald, W. (1983). BANGKOK: The Political Economy Of A Hyper Urbanized Primate City, Hong Kong Journal of Public Administration 5(1)

Galiani, S. \& Sukkoo, K. (2008). The Law of the Primate City in the Americas. Washington University in St. Louis and NBER 
Gilbert, A. \& Gugler, J. (1996). Cities, Poverty and Development urbanization in the third world, translated by Prviz nassri Karimi, Tehran Municipality International Office and Public Relations Press, First Edition

Gupta, S. \& Rayadurgam, I. (2008). URBAN GROWTH AND GOVERNANCE IN SOUTH ASIA, Societies in Political and Economic Transition: South Asia Perspectives 2007-08. Macmillan India.

Henderson, J. V. (2000). The Effects of Urban Concentration on Economic Growth, NEBR Working Paper \#7503.

Jefferson, M. (1939). The Law of the Primate City. Geographical Review, 29, pp. 226-32.

Kabir, A. \& Parolin, B. (2007). Planning and development of Dhakaa story of 400 years, 15 th international planning history society conference.

Kabiru, W. C. (2013). Transitions to adulthood in a high fertility context: The case of Sub-Saharan Africa, United Nations Expert Group Meeting On Fertility, Changing Population Trends And Development: Challenges And Opportunities For The Future.

Mirdal, G. (1987). Asian Drama, translated by Amiri M., Tehran: Institute of Technology Press, First Edition.

National Statistical Office of Thailand. (2010). Executive Summary The 2010. Population and Housing Census land markets.

Nwanna, C. R. (2012). Gentrification in Lagos State: Challenges and Prospects British. Journal of Arts \& Social Sciences. 5(2), p. 163

Olawepo, R. A. (2010). Perspectives on Urban Renewal and Transportation Development in Lagos: Implications for Urban Development in Nigeria. An International Multi-Disciplinary Journal, Ethiopia 4(1)

Overman H.G., \& Venables, J. A. (2005). Cities in the developing world. London School of Economics and CEPR

Porio, E. (2009). Urban Transition, Poverty, and Development in the Philippines, Department of Sociology and Anthropology Ateneo de Manila University.
Piran, P. (1989). Urban primacy and dominance in the Third World: a brief review of theoretical perspectives, Journal of Political Economy of Information, 34

Potter R. B., Evens S.L. (2005). The city in the developing world, Qumars Irandost and colleagues translated, published the first edition of the country's municipalities.

Rezaei, R., \& Pour Ahmed A. (2009). The concentration of economic activity role of the increasing population of Tehran Metropolis, Journal of Human Geography 1(3)

Roberts, B. R (2003). Comparative Systems: An Overview, University of Texas at Austin United States of America Conference on African Migration in Comparative Perspective, Johannesburg

Rodgers, D., et al. (2008). Latin American urban development into the 21stcentury Towards a renewed perspective on the city

Weeda, S. (2012). The Negative Effects Of Hernando De Soto's Mystery Of Capital, Radboud University Nijmegen: Master Human geography Globalization, Migration and Development by the Center for Planning and Architectural Studies and Research, Tehran.

The world bank annual report (2003)

Un Habitat. (2010). The state of African cities 2010, governance, Inequality and Urban UN/POP/EGM-URB/2008/09, 15 October 2007

UN-HABITAT (2010). State of the world's cities

UN-Habitat. (2011). Cairo - a City in Transition Cities and Citizens Series (Series title)

Wessels, G., Pardo, F. C., \& Bocarejo, P. J. (2012). BOGOTÁ 21. Towards A World-Class, Transit-Oriented Metropolis, ISBN: 978-958-57674-0-9

Zebardast, E. (2007). Evaluation of urban primacy developments in Iran. Fine Art Magazine, 29 